\title{
Study on the Characteristics of the Chinese Students' Critical Thinking
}

\author{
Shi Jing \\ School of Culture and Media, Central University of Finance and Economics, Beijing, China
}

\section{Email address:}

shijing0707@163.com

\section{To cite this article:}

Shi Jing. Study on the Characteristics of the Chinese Students' Critical Thinking. Higher Education Research. Vol. 5, No. 3, 2020 , pp. 94-102. doi: $10.11648 /$ j.her.20200503.14

Received: May 16, 2020; Accepted: May 29, 2020; Published: June 4, 2020

\begin{abstract}
The critical thinking trait is the premise and foundation of innovative thinking, and has become the necessary ability and core quality for cultivating innovative talents. Different scholars have different understandings about the definition and constituent elements of the characteristics of thinking and critical thinking. Their common view is that the characteristics of thinking is the intention and will of thinking activity, and the characteristics of critical thinking is the individual tendency of critical thinking. Facts have proved that the general lack of critical thinking ability of Chinese students has become a defect in their qualities. Thus, the education of critical thinking should start from primary education, and the cultivation of critical thinking at university stage should strengthen the existing foundation laid in primary and secondary schools. Faced with the educational growth process of these potential innovative talents of the Chinese students, this paper puts forward five countermeasures and suggestions on the cultivation of critical thinking characteristics, which have theoretical and practical significance for promoting the reform of critical thinking teaching, improving the level of critical thinking of the Chinese students, improving the qualities of cultivating innovative talents and promoting independent innovation.
\end{abstract}

Keywords: Characteristics of Thinking, Critical Thinking, Innovative Talents, Teaching Reform

\section{Introduction}

Improving independent innovation capability and building an innovative country have become the core goals of the national development strategy and an important indicator of improving China's overall national strength. The core of an innovative country is innovative talents. The thinking qualities of innovative talents are the core elements for creating innovative talents, among which the relationship between innovation and critical thinking is complementary [1]. The article first sorts out the definitions and constituent elements of Thinking Disposition and critical thinking characteristics, then analyzes the confusion and problems that Chinese students have in the process of critical thinking training, and finally puts forward critical strategies and policy suggestions, including the following, to take the empirical and research learning as the target in the process of cultivation of critical thinking, to change the starting point of teaching, to pay attention to the role of real learning situations for the cultivation of critical thinking, to formulate and carry out the common academic and skill standards, and to measure the educational level of critical thinking through measurement in order to achieve a systematic and all-round promotion of education actions in critical thinking.

\section{Thinking Disposition}

Disposition are a trend of thought and action. They are different from ability and skill, and show a certain tendency. Thinking disposition are a focus of research in related fields such as logic, psychology, thinking science, cognitive science, and philosophy of science, etc., and have made great progress respectively in theory and method. Dewey J. was the first scholar to propose thinking disposition. He emphasized "The cultivation of thinking skills and disposition is critically necessary for a democratic society. Teachers often focus on the instillation of knowledge and skills, and ignore the cultivation of students' interests and habits-formation." [2] In the field of education, since the 1990s, many scholars have begun to pay attention to and study the disposition related to thinking, and promote the thinking level of innovative talents by training students' thinking disposition. There are mainly 
three different views on the definition and constituent elements of thinking disposition.

The first point of view: contrast of thinking disposition and skills, it is the tendency and intention of the thinking process. Educator L. G. Katz proposed "Disposition are repetitive patterns of behavior in a situation without stress, forming a mental habit under the control of consciousness and will. They have a purpose and aim at a broader goal." [3] In this process, the acting subjects do not necessarily be aware of the intervention of motivation and intention, just like the disposition of children's curiosity which is the reflection done by children with repeatedly respond to a certain problem or environment through questioning and inquiry. Therefore, disposition can be understood as the subjective will to consciously point to the goals and situations in order to achieve a certain goal. In the course of education, we should selectively strengthen positive disposition and weaken negative disposition. Educational Philosopher R. H. Ennis proposed 14 kinds of thinking disposition [4], as shown in Figure 1.

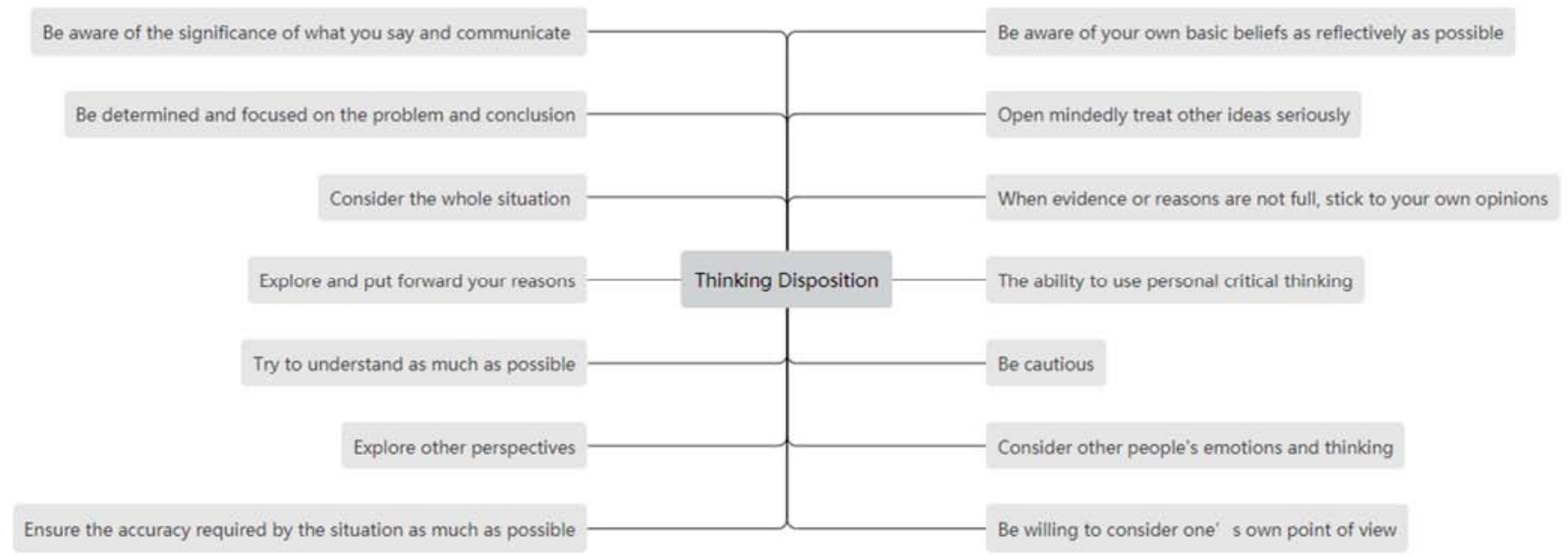

Figure 1. 14 kinds of thinking disposition.

Paul (R. Paul) from University of California thinking disposition as mental characteristics, enumerating the following 9 mental characteristics in Figure 2:

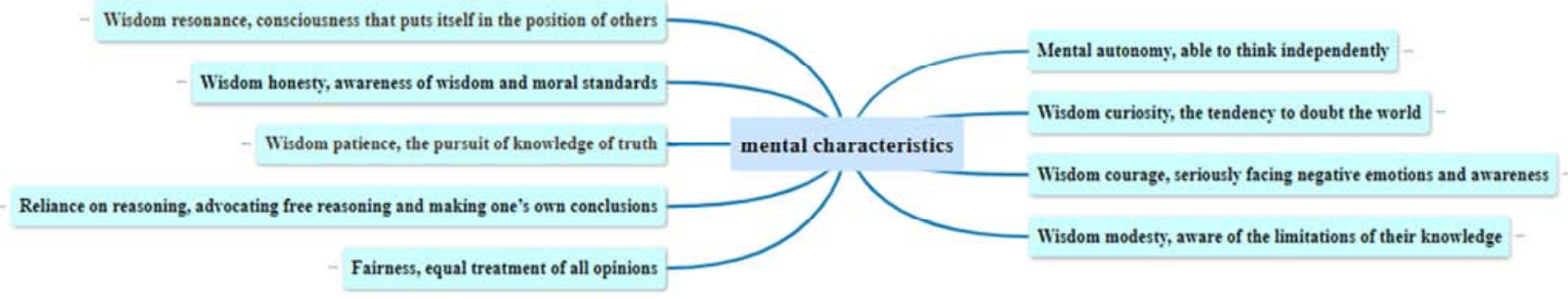

Figure 2.9 kinds of mental characteristics.

The second point of view: thinking disposition include the willingness to think and the skills to use thinking. S. Norris proposed that thinking disposition are not only the desire or preference of thinking, but also that individuals must develop the habit of applying a certain skill [5]. Psychologist G. Salomon summarized the four components of the disposition: 1. attitude; 2. intention; 3. preference; 4 . ability to make preference come true. He regards mindfulness as the core thinking disposition, and its constituent elements are: 1. a positive attitude to complicated situations; 2 . unconventional preferences or unique preferences; and 3. exploration of the tendency of the situation and creation of situation to meet personal preferences [6].

The third point of view: thinking disposition are composed of three elements, such as sensitivity, intention and ability. This is the definition of Trinity proposed by D. Perkins, a psychologist at Harvard University.

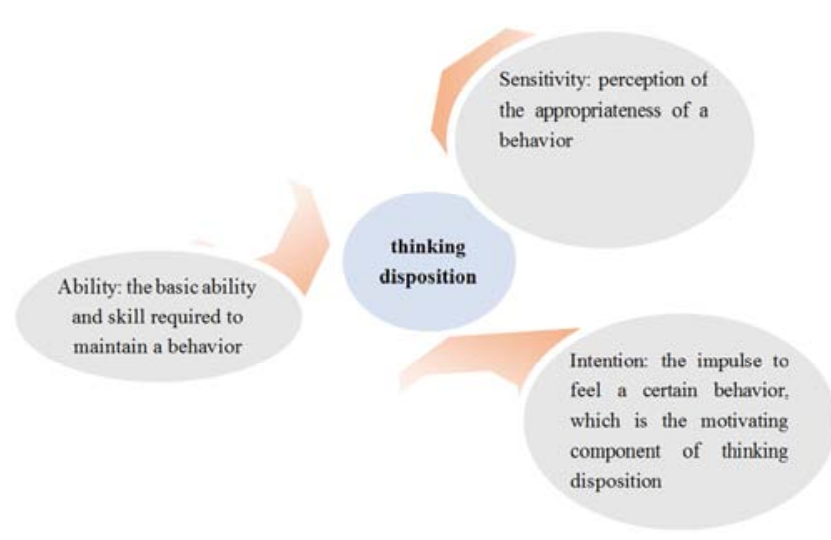

Figure 3. Components of thinking disposition.

These three elements of thinking disposition must appear in order to produce actions of thinking disposition. Perkins and S. 
Tishman listed 7 positive thinking disposition, each of whom contains three elements. It is the best thinking to show these 7

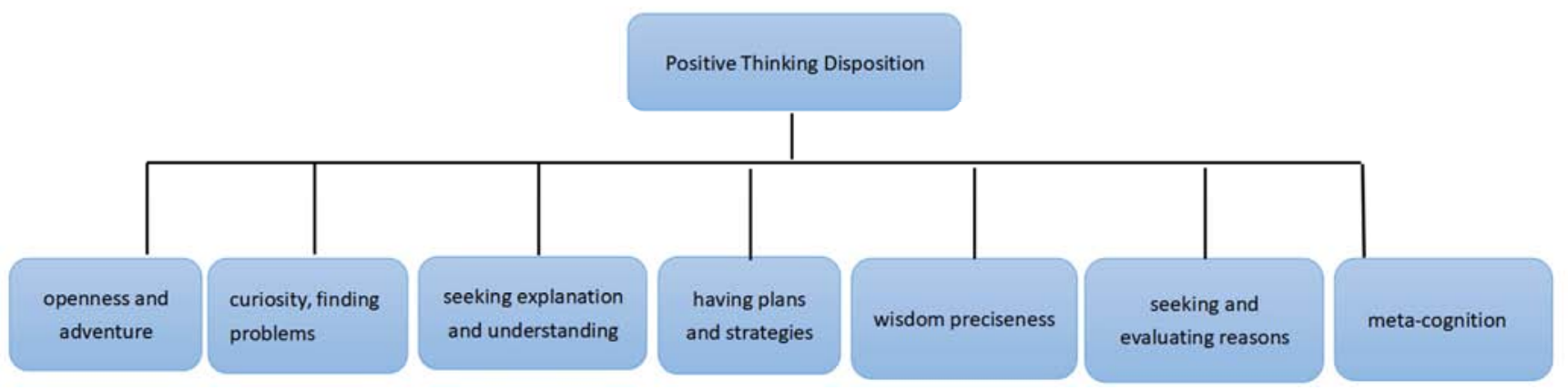

Figure 4. Seven positive thinking disposition.

From the above analysis of the three viewpoints of thinking disposition, such a consensus can be drawn: thinking disposition are the intention and willingness of thinking activities, and sensitivity is the main component of thinking disposition. Regarding positive thinking disposition, everyone believes that an open mind, independence, curiosity, persistence, self-confidence, metacognition, and etc. can form positive thinking disposition [7].

\section{Critical Thinking Disposition}

The term criticism has a strong emotional color, with irrational colors such as questioning, distructiveness and aggression. From the literal meaning of critical thinking, many people understand it as negation and attack, but in fact these are not consistent with critical thinking. Regarding the nature of critical thinking, there is widespread chaos and deviation in understanding. Critical thinking should clarify two misunderstandings: first, it is not a negative opinion and criticism of faults drawn by taking the words literally; second, it is not a simple reasoning skill. Critical thinking is a purposeful, self-calibrating judgment, which is expressed in interpretation, analysis, evaluation, inference, etc., as well as explanations of judgment arguments, standards, and context.

The theory of critical thinking was born in different historical and cultural backgrounds, China and the West have established different complex structural systems, so far it is impossible to give a unified definition that all disciplines agree on. The famous education philosopher William Hare reminded that when dealing with a rich concept with strong vitality, beware of brief definitions, it is almost impossible to find a general formula [8]. Danny Weil vividly metaphorizes that the definition of critical thinking cannot be digged out endlessly, so if one day its final definition is give, then it is the time of death of critical thinking [9]. Paul $\mathrm{R}$ W. introduces the complex definitions of critical thinking by classifying into Tendenza, Skill Faction, and Tendency-Skill Faction to [10], see Figure 5 below:

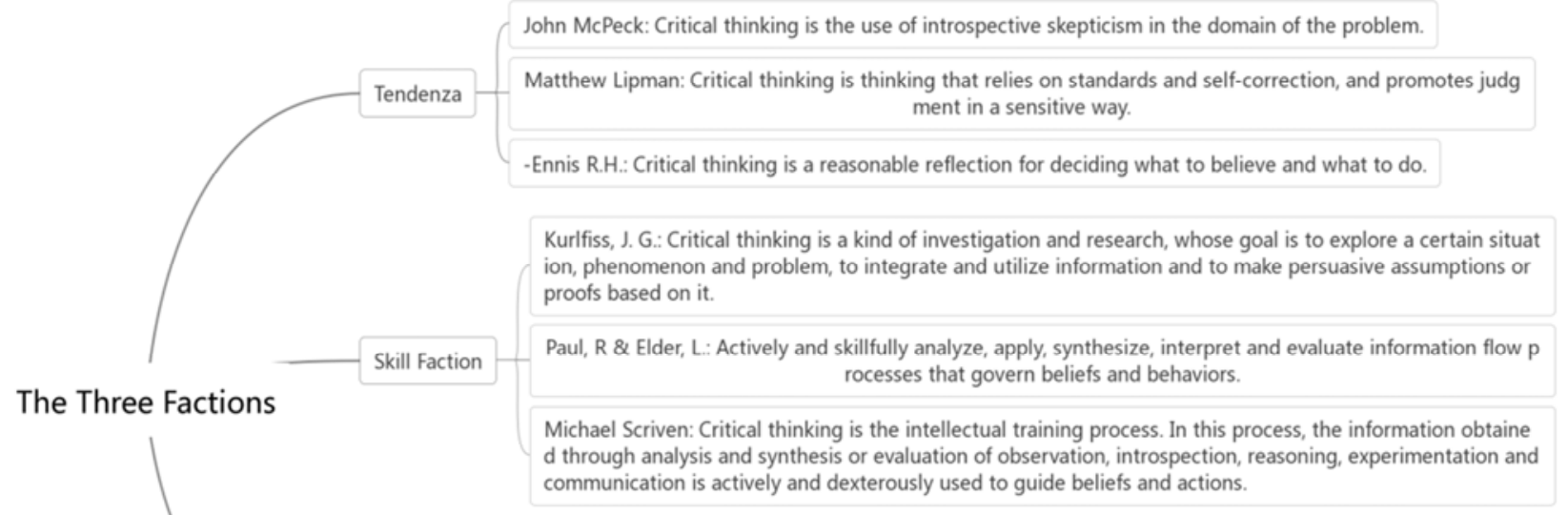

Stephen D. Brookfield: Critical thinking requires questioning the hidden assumptions in our habits, the habit ual way of thinking and acting, and starting thinking and acting on the basis of critical questioning

Bailin, S: Critical thinking is to think deeply about what you believe or how to act.

In 1991, the American Philosophical Association used the Delphi method to arrive at a generally accepted de finition: critical thinking is a purposeful, self-calibrating judgment. It manifests itself as interpretation, analysi $\mathrm{s}$, evaluation, inference, and interpretation of the concepts, methods, standards, arguments, or contexts on w hich judgment depends.

Figure 5. Definition of Critical Thinking. 
diversity. Critical thinking is a way of thinking that analyzes, evaluates and criticizes based on reliable arguments. It mainly includes thinking tendencies and skills. In this respect, the validity and credibility of arguments and talking points are emphasized in the process of dynamic self-reflection and self-management [11].

Critical thinking disposition is reflected in the individual tendency of critical thinking, which is the mental preparation state, willingness and tendency of conscious judgment. It can activate the individual's critical thinking consciousness and promote the individuals to look at the problem with the perspective of examination and think purposefully. The elements of critical thinking disposition can help us to understand the definition of critical thinking characteristics in depth. These 7 elements are shown in Figure 6.

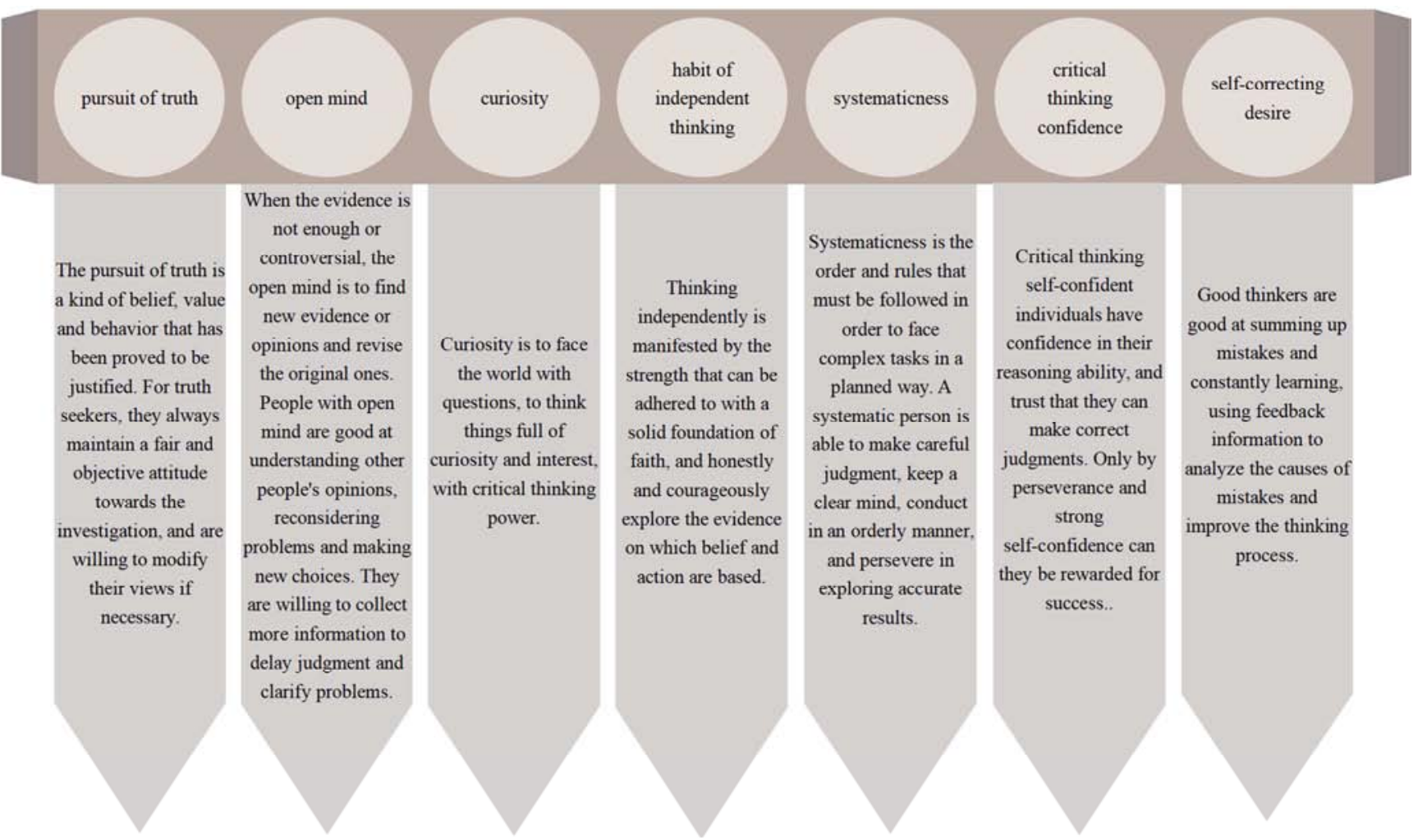

Figure 6. Elements of Critical Thinking Characteristics.

\section{Puzzles and Problems in the Cultivation of Critical Thinking of Chinese Students}

The level of rational thinking is a sign of the progress of social civilization. The development and promotion of critical thinking requires students to be able to identify, analyze, compare, summarize and summarize basic language and literature phenomena, and to explain their views rationally and reasonably. And what are the root causes of the phenomenon of weak creativity and clinging to stereotypes reflected by Chinese students?

\subsection{Defects of Basic Education for Chinese students}

In recent years, Chinese universities have paid more and more attention to the development of critical thinking education for college students, and have set up courses to explain critical thinking knowledge and skills, but the teaching effect is not ideal. It is difficult for students to form conscious rational thinking habits through the study and practice of critical thinking courses. When the teachers explicitly ask students to think critically, they do better. Once out of the classroom, when solving practical problems in learning and life, they often unconsciously act in accordance with their original thinking and thinking habits. The reason is that the period when a person's thinking habits are shaped is at the elementary and junior high school level. It is not possible to teach critical thinking courses only at the university. It is necessary to critical thinking education should be set at the basic education stage, that is, starting from elementary and middle school. The critical thinking course at the university level is to strengthen the existing foundation, so that the critical thinking ability of students can be transformed into a basic quality. Just as the problems reflected in "Qian Xuesen's Question" are also the problems that has not been solved in China's basic education and exam-oriented education to a certain extent, the root of the problems lies in the basic education.

\subsection{Defects of Chinese Students' Quality}

The SAT Examination is an "Academic Ability Assessment Test" sponsored by the College Board of the United States. According to the data analysis shown in the annual analysis report of SAT in China, the main reason for the low average score of Chinese students lies in the two 
parts: reading and writing in examining the ability of students' critical thinking. Chinese students need to use critical thinking to separate the appearance to explore the hypothesis and premise of the conclusion, and to compare the author's different views when they do such type of problems as comparison and evaluation of the argument, they lose the most points. From an educational perspective, the concept of Chinese education is based on survival-competitive exam-oriented education. The students are good at answering questions on various test papers, ignoring the training of critical thinking characteristics that exert innovative capabilities [12]. Facts have proved that the lack of sufficient critical thinking training for Chinese students as a whole has become the main factor that limits Chinese students' academic ability and causes quality defects.

\subsection{Defects of Learning Methods of Chinese Students}

Critical thinking education requires Chinese students to have the abilities of problem-solving, reasoning and practical development. It should pay attention to the cultivation of the following intellectual virtues and abilities of discernment and development, which are also the main characteristics of critical thinking and the basic standards of academic research and scientific development.

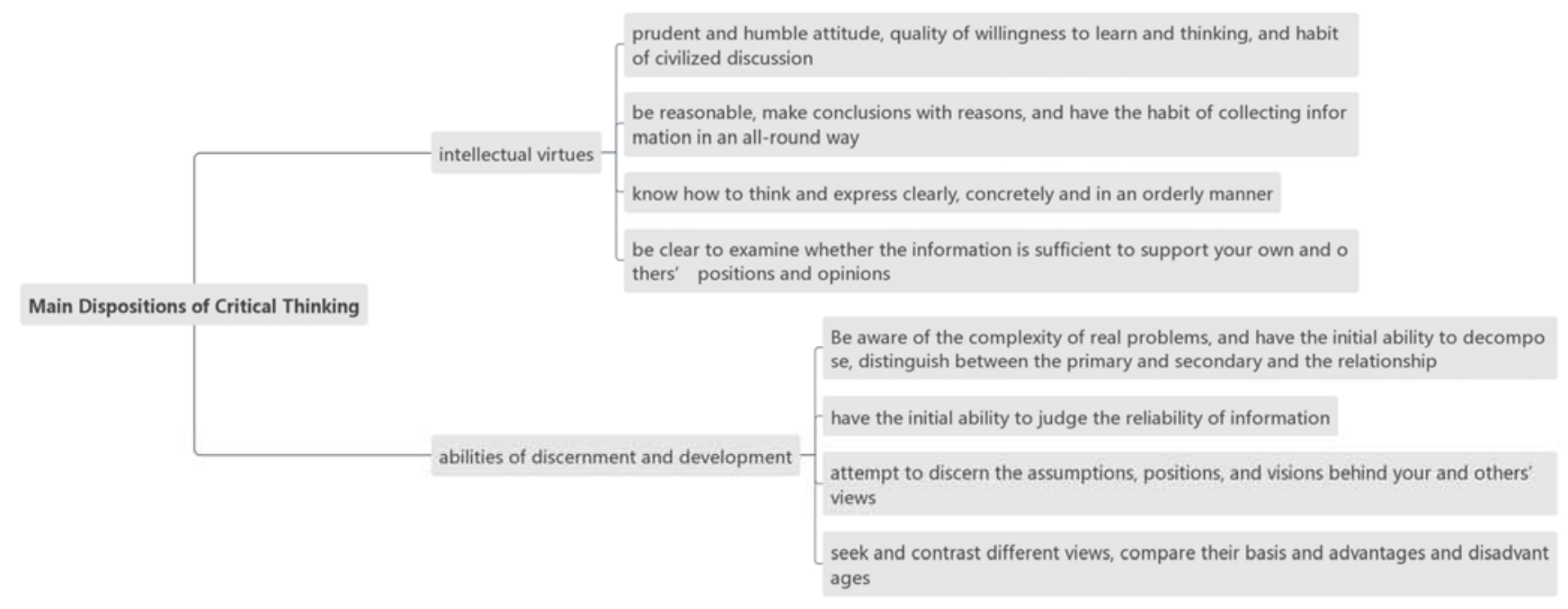

Figure 7. Main Dispositions of Critical Thinking.

Among the eight virtues and qualities listed in Figure 7, the ability to distinguish the assumptions, positions, and perspectives of your opinion from those of others, as well as the ability to seek and contrast different viewpoints, and to compare the two aspects of their theoretical basis, and advantages and disadvantages are the weakest aspects of the Chinese students. The reason for this is that Chinese students do not use the inquiry-based learning method in the learning process of various subjects. In the curriculum of college, middle and elementary schools, teachers rarely use the combination of empirical and inquiry methods for teaching, in which two following goals are lacked, first, in the content of teaching courses, there is no special critical thinking textbook, and there is little information in each subject to encourage students to analyze, judge and reason, and as well as know the different concepts, theoretical backgrounds and sources of knowledge generated; second, in teaching methods, teachers rarely use critical thinking education methods connected with reality, and rarely use the teaching method of rational thinking that combines questioning, interaction and inspiration, and thus cannot achieve true edutainment. In studying, students have such tendencies as pursuit of breadth of knowledge, thinking not in depth, and putting forward questions less often. Therefore, they are often imprisoned by the one-sided appearance of problems and do not explore the root of the problem.

\section{Cultivating Strategies and Suggestions for Chinese Students' Critical Thinking}

When making up for the shortcomings of Chinese students' literacy, we should not only consider the needs of the times, but also combine the characteristics of Chinese students to explore ways and methods that conform to the reality of the Chinese education.

\subsection{Taking Evidence and Research-based Learning as the Target}

The goal of evidence and research-based learning is to focus on cultivating students' analytical ability, reasoning and argumentation ability based on facts, etc. Specifically, teachers may guide students to conduct evidence and research-based studies, learn to write research papers, conduct scientific research and write argumentative essays, and teachers may also guide students to write persuasion essays, of which unlimited length and in-depth and well-grounded content, are required. Imagine that if students begin to receive academic and scientific research training from primary school, then enter university, and then further 
enter graduate stage to learn, they would surely know how to carry out academic research. If we could do so, such kind of guide should be required in our education from kindergarten to university. In the kindergarten stage, children should be encouraged to play freely and create freely in different activities. The kindergarten teachers should cultivate the children in planning and rethinking in games in order to improve their critical thinking and logical thinking skills. At the elementary school level, teachers would no longer allow students to memorize by rote their knowledge, focusing on guiding students how to think about problems and teaching them how to find answers in different fields. The schools would try to improve the students' abilities in language expression, critical thinking and reasoning with the help of classroom teaching, organizing debate and other forms of classroom activities. by middle school, teachers would encourage students to learn how to question and enhance the cultivation of students' ability of critical thinking. The teachers would put forward questions and then guide students to consult relevant materials from the library and network resources to get their own answers instead of giving students ready-made answers, and ask students to give full play to their own imagination to propose their own very good ideas. By Junior high school, schools could set up research-oriented classes to provide meticulous teaching guidance for students to find problems, analyze problems, solve problems, and cultivate critical thinking skills. Fortunately in universities, many colleges and universities have set up courses such as "Critical Thinking", "Introduction to Logic", and "Mathematical Logic" specially to train students in logical thinking and critical thinking. In the entire university education, all majors have requirements to write survey reports, research papers, held debates and entrepreneurial competitions to achieve the goal of training and improving the abilities of logical thinking, critical thinking and innovation of the students [13]. Figure 8, taking Chinese language and mathematics learning as an example, lists the skills required for basic education, proposes corresponding competency goals, core literacy and teaching requirements for cultivating students' critical thinking.

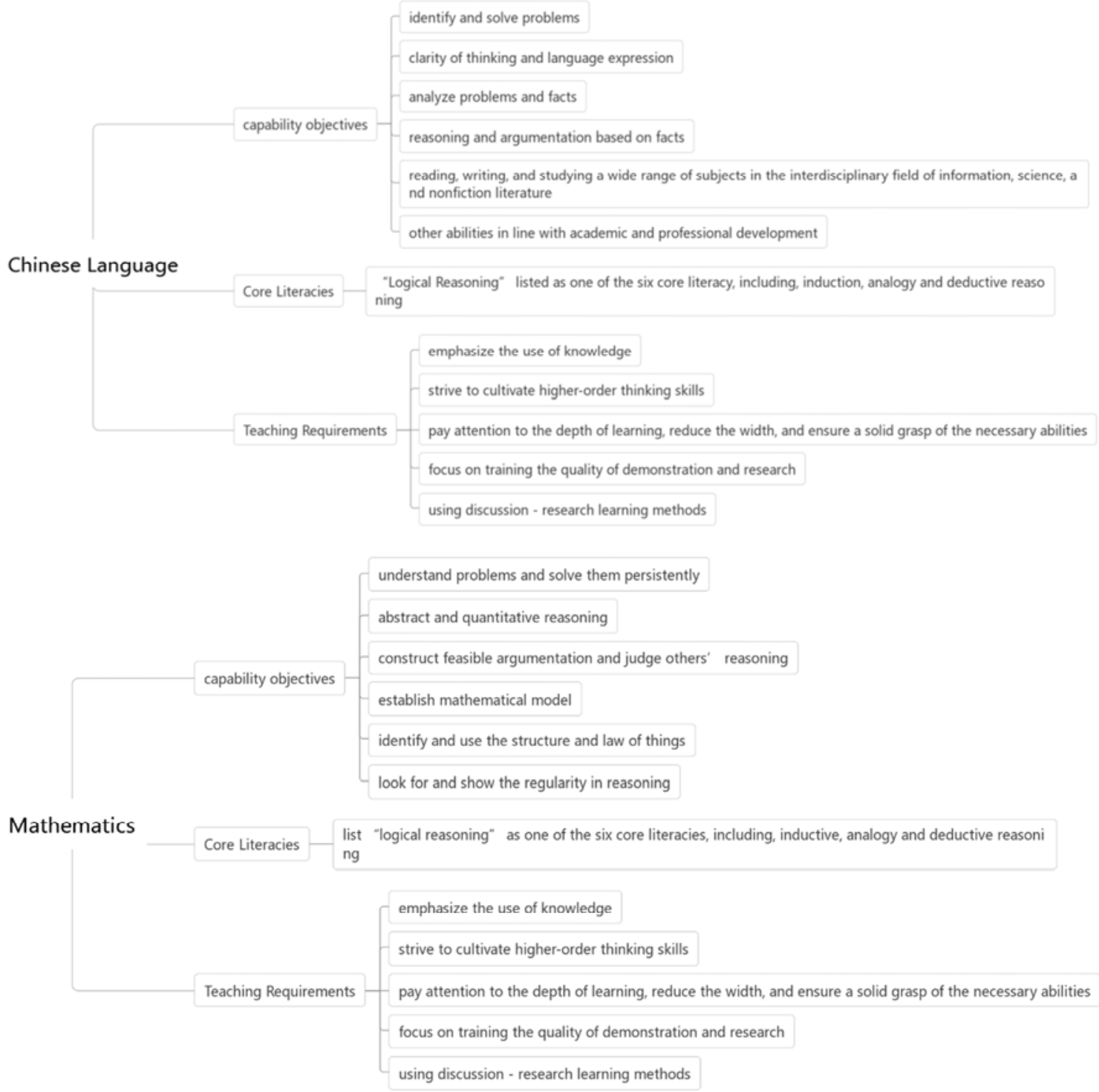

Figure 8. The Ability Requirements of Chinese Language and Mathematics in Basic Education. 


\subsection{Change the Teaching Model with Real Learning Situations}

In critical thinking education, it is important to pay attention to the positive effect of real learning situations on the cultivation of critical thinking, and change the original traditional teaching mode, which can be done from the following aspects. First of all, the starting point of teaching should change the way of explaining basic principles and concepts first, and introduce case teaching and problem guidance to begin a course. Second, increase the authenticity of the learning situation. The real situation can fully arouse the enthusiasm and creativity of students' independent learning. The creation of a learning situation depends on the preparation of teaching equipment and other material aspects, the mental state of teachers' participation consciousness, cooperation attitude, etc., which can better promote the learning and development of students. Students are learning knowledge not only by teachers' teaching, but also in a certain real situation, through their participation and devotion to these activities that require motivation and serious thinking, by fully displaying their thinking characteristics and with their conscious thinking habits gradually cultivated, and their pleasure of thinking enhance in solving problems encountered in real life and learning, can they actively learn and master knowledge and skills [14]. R. Fazio has proposed five factors of strength of thinking disposition, including: (1) direct experience; (2) sensory experience; (3) emotional response; (4) free choice behavior; (5) attitude recurrent. In the teaching process, only when they encounter and solve actual problems in real situations by identifying many different points of view and collecting evidence that supports or refutes a certain point of view and during the course of problem solving with the enhancement of the strength factors of thinking disposition, can the students get annealed.

\subsection{Cultivate Elites by Formulating and Implementing Common Academic and Skill Standards}

In China, the education methods and standards of various provinces, cities, counties, and even villages differ to varying degrees, and the teaching content and objectives are also different. The backgrounds of culture, class and economy have a certain influence and restriction on critical thinking education. In the face of the current situation that critical thinking has become an important defect in the qualities of Chinese students and regional differences, it is urgent to formulate a common academic and know-how standards that all provinces must follow, the essence of its core standard is to teach critical thinking and develop the ability of deep analysis. There is no need to specify a unified curriculum and bibliography for each province. The specific curriculum and bibliography will be set by each province, accompanied by a standard test that specifically tests critical thinking. The test is different from the traditional test and can be performed on computers, in which especially interactive problem-solving exam questions should be included, which requires students to write the answers and demonstrate them. The significance of implementing this common standard is that it can expand China's creative elite class and develop China's science and technology faster.

\subsection{Accurate Assessment to Measure the Educational Level of Critical Thinking}

It has been a relatively short period of time for critical thinking research to begin in China, and most of the evaluation tools currently used are directly translated and used foreign measuring tools. Due to the historical and cultural differences between China and the Western countries, the critical thinking assessment tool in the West is obviously not completely suitable for the thinking dispositions of the Chinese people, resulting in the lack of empirical support for the research results of critical thinking assessment. On the basis of referring to the existing achievements by the Western countries, we must focus on breakthroughs to build a measurement tool that truly suits the characteristics of Chinese thinking [15]. Because critical thinking education is of delayed nature, long-term, and potential, it is not enough to measure the development level of critical thinking education by measuring the results of critical thinking education, so it is also necessary to measure the level of critical thinking education of Chinese students as comprehensively as possible by measuring the indicators of critical thinking education process and input factors and etc., and accurately set the starting point of education, the difficult process, the framework system and the training goals.

\section{Measures to Promote Critical Thinking Education in all Directions}

The implementation of critical thinking education in the basic education stage is not only an educational issue, but also involves cultural, social and spiritual aspects, as well as multiple links including the formulation of curriculum standards, examinations and evaluations. It is a comprehensive and profound systemic educational reform. Specific measures are mainly implemented from two directions.

\subsection{Teacher Training}

In the process of pushing forward the reform of education and teaching, primary and secondary schools should deepen the training of teachers' critical thinking theory and application ability. Teachers are the key role in the implementation of critical thinking education. They have changed the traditional sense of knowledge imparters and become the leading organizers and mentor collaborators in the teaching activities. Only when teachers can teach critical thinking courses professionally, can students develop critical thinking qualities through this course. For the study and training of teachers' teaching methods, first of all, teachers should have the critical spirit of modesty, rationality and openness, pay attention to the integration of moral education 
and intellectual education, and change into the trinity role of cognitive activity subject, Socrates and coach. At the same time, it is suggested that the Teacher Development Center of the Ministry of Education increase the requirements for inspection of critical thinking disposition in the training of new teachers and teacher qualification examinations, and establish a strict teacher assessment mechanism.

\subsection{Examination Reform}

On the one hand, add questions that need reasoning and thinking, and require examinees not only to choose answers, but also to demonstrate the reasons for choosing the option. On the other, increase the writing of analytical argumentation papers. It is required that the writing of the thesis must be justified reasonably, and the thesis should be proved or falsified according to its arguments and reasoning, refuting fallacies and searching for loopholes. The essay writing score can be used independently as an important reference mark for key universities to measure a student's future academic ability, providing a truly meaningful credibility indicator for college admissions, and essay scores can be used as a priority measure for admission. In recent years, the Chinese language of the college entrance examination has focused on examining students' use of logical rules and methods of inquiry and questioning to examine reading materials, and examining students' logical thinking and creative thinking abilities, and thinking characteristics of criticalness and originality. The college entrance examination provides a wealth of thinking space and logical relationships in the materials of the material composition, guides students to understand problems from different angles, think independently, explore the question, and examine the thinking characteristics of students. In the college entrance examination, students are encouraged to think actively, whether they agree or disagree with the points given in the problem set, as long as the argument is reasonable and well-founded, it can be scored [16]. The college entrance examination tests students' critical thinking dispositions and abilities from different angles, and promotes the development of students' critical thinking characteristics.

\subsection{Personality Perfection}

By studying personality characteristics, the regression analysis of the critical thinking of college students has proved that there is a certain correlation between personality traits and critical thinking of students. Among which there is a negative correlation between neuroticism and psychoticism and critical thinking, while introversion and introversion presents a positive correlation with critical thinking. The stronger critical thinking ability the students have, the more stable and extroverted their characters will be, and the better they will be at self-control and the faster they will adapt to the external environment [17]. The cultivation of critical thinking has become an important training objective of education and even in higher education. In order to make students develop good habits of critical thinking, institutions of higher learning, middle and primary schools can start with the cultivation of students' character, shape the students' optimistic and positive personalities according to their aptitude. And different critical thinking training methods are adopted for students with different personality traits in order to guide students to be willing to explore problems. Anyway, we should jointly promote the cultivation of students developing better critical thinking quality. At the same time, we can add new courses of personality cultivation and mental health in the school's teaching plan. By allowing students to objectively and truthfully know and understand their personality characteristics, schools need to establish a management and supervision mechanism for perfecting personality, and raise students' awareness of self-perfection and take the initiative to carry out a variety of extracurricular activities to promote the improvement of college students' personality, and then to promote the development of college students' critical thinking.

\section{Conclusion}

Quality education emphasizes the spirit of innovation and practical ability, which is inseparable from critical thinking education. In order to cultivate high-quality innovative talents, the country must cultivate people with critical thinking and creativity. We should take the cultivation of critical thinking ability as the focus of education, and take the development and expansion of critical thinking education as the important goal of education. It is of great theoretical and practical significance for the reform of critical thinking teaching and the improvement of Chinese students' critical thinking level to carry out the research in a wide range on the cultivation of critical thinking in China.

\section{References}

[1] Chen Bo, Critical Thinking and the Cultivation of Innovative talents [J]. China University Teaching, 2017 (3). P. 22.

[2] Dewey J. How We Think: A Restatement of the Relation of Reflective Thinking to the Educative Process [M]. Boston: D. C. Heath and Company, 1933. 58.

[3] Katz L G. Disposition: Definition and Implications for early Childrenhood Practice [DB/OL]. http://ceep.crc.uiuc.edu/eecearchive/digests/1993/katzdi93.ht $\mathrm{ml}$.

[4] Ennis R H. Assessing Critical Thinking Disposition: Theoretical Considerations [J]. Paper Presented at Annual Meeting of the American Education Research Association. New Orleans. LA., 1994.

[5] Norris S P. The Meaning of Critical Thinking Test Performance: The Effects of Abilities and Disposition on Scores [A]. D Fasko. Critical Thinking: Current Research, Theory, and Practice [C]. Dordrecht, The Netherlands: Kluwer, 1994.

[6] Salomon G. To be or not to be (mindful). Presented at the Anuual Meeting of the American Educational Research Association. New Orleans, LA. 1994. 
[7] Zhu Xincheng. On the Cultivation of Thinking Characteristics and Teaching Reform [J]. Curriculum, Teaching Material and Method, 2016 (1), PP. 26-27.

[8] William Hare. Critical Thinking as an Aim of Education $[\mathrm{M}] / /$ Roger Marples (ed.). Aim of Education. New York: Routlegde, 2002: 85-99.

[9] Joe L. Kincheloe and Danny Weil (eds.) Critical Thinking and Learning: An encyclopedia for parents and teachers [M]. London: Greenwood Press. 2004.

[10] Paul R W. Critical tinking in North America: A new theory of knowledge argumentation, 1989.

[11] Li Ying. Critical Thinking Research [D]. Master's Thesis. Nankai University, 2013, p6.

[12] Dong Yu. Competing for Critical Thinking [J]. People's Education. 2015, pp. 14-15.

[13] Du Guoping. Test and aAnalysis of Logical Thinking Ability [J]. On Academic Foreword. 2012 (12), p. 323.

[14] Facione P A, Sanchez C A, Facione N C, Gainen J. The Disposition toward Critical Thinking [J]. Journal of General Education, 1994. 44 (1): 1-25.

[15] Shi Jing. Measurement and Cultivation of Critical Thinking [J]. Jianghuai Tribune. 2017 (5), p. 133.
[16] Gu Zhichuan. How to Implement Core Literacy in the Chinese Language of College Entrance Examination [J]. China Examinations. 2018 (10), pp. 49-50.

[17] Zeng Jinling. A study on the Status Quo of Critical Thinking of College Students and Its Correlation with Personality Dispositions and aAchievement Goals [D]. Journal of Inner Mongolia Normal University, 2013. 5. 20, p22.

\section{Biography}

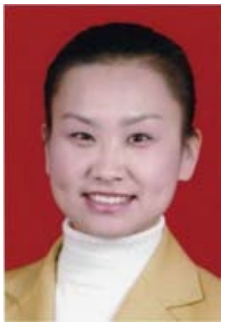

Shi Jing (1980-): female, was born in 1980, in Zhengzhou City, Henan Province, China. Since 2003, she had been studying modern logic with Professor $\mathrm{Na} \mathrm{Li}$, a famous logician in China. In 2009, she graduated from the school of philosophy of Nankai University with a Ph. D. and is now an associate professor of the School of Culture and Media of the Central University of Finance and Economics and a Master's Supervisor of Logic. Her main study field is in symbolic logic and philosophical Logic. 